\title{
Tornar-se mãe de um segundo filho: a experiência do muito e do limite
}

\author{
Becoming a second-time mother: the experience of too much and the limit \\ Ser madre de un segundo hijo: la experiencia de lo mucho y del límite \\ Joana Rodrigues ${ }^{1,2}$ in https://orcid.org/0000-0002-9323-9410 \\ Maria Antónia Rebelo-Botelho ${ }^{1,2}$ (1) https://orcid.org/0000-0001-7356-2053
}

Como citar:

Rodrigues J, Rebelo-Botelho MA. Tornar-se mãe de um segundo filho: a experiência do muito e do limite. Acta Paul Enferm. 2021;34:AAPE02404.

DOI

http://dx.doi.org/10.37689/actaape/2021A002404

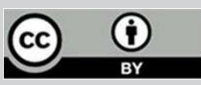

Descritores

Mulheres; Mães/psicologia; Relações familiares;

Segundo filho

Keywords

Women; Mothers/psychology; Family relations;

Second child

Descriptores

Mujeres; madres/psicologia; Relaciones familiares;

Segundo niño

Submetido

15 de Agosto de 2019

Aceito

2 de Dezembro de 2020

Autor correspondente

Joana Rita Guarda da Venda Rodrigues E-mail: guarda.joana@gmail.com

\section{Resumo}

Objetivo: Compreender a experiência vivida da mulher ao tornar-se mãe de um segundo filho.

Métodos: 0 desenho do estudo adota uma metodologia qualitativa com abordagem fenomenológica hermenêutica. A colheita de dados foi realizada em duas creches da área de Leiria. Foram realizadas entrevistas fenomenológicas a onze mulheres, com um segundo filho, de idade compreendida entre os 18 e os 24 meses. As atividades desenvolvidas no processo de análise de dados tiveram em consideração as orientações de Van Manen.

Resultados: Tornar-se mãe de dois filhos emergiu como "uma experiência completamente diferente", na medida em que dois filhos, uma família, exigem a realização de inúmeras atividades pela mulher, que a conduzem à experiência do muito e do limite, do ir além de si, na procura de um novo eu, que quer encontrar o essencial. A procura de ajuda é o caminho percorrido pela mulher, num tempo em que precisa de mais apoio. Conclusão: Este estudo abre uma nova perspetiva de compreensão do fenómeno de transição da parentalidade podendo assim ter impacto na prática clinica dos enfermeiros.

\section{Abstract}

Objective: To understand the woman's experience of becoming a second-time mother.

Methods: The study design adopts a qualitative methodology with a hermeneutic phenomenological approach. Data collection was performed in two daycare centers in the Leiria area. Phenomenological interviews were conducted with 11 women with a second child aged between 18 and 24 months. Van Manen's guidelines were taken into account in the activities developed in the data analysis process.

Results: Becoming a second-time mother emerged as "a completely different experience" in that two children and a family require the performance of numerous activities by the woman, which leads her to the experience of too much and the limit, of going beyond herself in the search for a new self who wants to find the essential. The search for help is the path taken by the woman at a time when she needs more support.

Conclusion: This study opens a new perspective of understanding the phenomenon of transition to parenthood and may have an impact on nurses' clinical practice.

\section{Resumen}

Objetivo: Comprender la experiencia vivida por una mujer al convertirse en madre de un segundo hijo.

Métodos: El diseño del estudio adopta una metodología cualitativa con enfoque fenomenológico hermenéutico. La recopilación de datos se realizó en dos guarderías de la zona de Leiria. Se realizaron encuestas 
fenomenológicas a 11 mujeres con un segundo hijo entre 18 y 24 meses de edad. Las actividades desarrolladas en el proceso de análisis de datos siguieron las instrucciones de Van Manen.

Resultados: Ser madre de dos hijos surgió como "una experiencia completamente diferente", en la medida en que dos hijos, una familia, exigen la realización de incontables actividades por parte de la mujer, que la conducen a la experiencia de lo mucho y del límite, de ir más allá de sí misma, buscando un nuevo yo que quiere encontrar lo esencial. La búsqueda de ayuda es el camino que la mujer atraviesa, en un momento en que necesita más apoyo.

Conclusión: Este estudio abre una nueva perspectiva de comprensión del fenómeno de transición de la parentalidad y puede tener impacto en la práctica clínica de los enfermeros.

\section{Introdução}

Tornar-se mãe de um segundo filho, enquanto transição, conduz a necessidades em saúde, na medida em que a mulher é impelida a incorporar novo conhecimento, a mobilizar novas capacidades e recursos, no sentido de se adaptar ao seu novo papel e à sua nova identidade. ${ }^{(1)}$ Compreender o modo como este fenômeno é vivido pela mulher, atendendo à complexidade inerente ao facto de ser pessoa singular, e enquanto "ser-no-mundo"(2,3) / "um ser-no-mundo"(4,5) em determinado tempo, permitirá ajudar a mulher a viver este momento. Esta ajuda facilita, por um lado o cuidado à criança e a integração deste novo ser no seio da família, como também o ajustamento da mulher a esta nova condição, de modo a ultrapassar a ansiedade e o stresse vividos neste momento de vulnerabilidade. ${ }^{(6,7)}$

"Ser mãe de um filho é diferente de ser mãe de dois", ${ }^{(8)}$ pois implica que a mulher receba o segundo filho no lugar que lhe é único, de modo a que essa criança se sinta confiante no ambiente que a acolhe. ${ }^{(8)}$ Esta é uma experiência onde estão envolvidos diferentes sentimentos e expectativas maternas, além de ser um processo de crescimento e transformação, ${ }^{(9)}$ que interfere com a sua posição na família, com a sua relação com o bebê, com o irmão e com o marido. ${ }^{(7,8,10-12)}$

A literatura sugere que a mudança vivenciada pela mulher que se torna máe pela segunda vez pode ser exigente e desgastante, levar à exaustão e a novas tensôes no relacionamento conjugal, ${ }^{(11-13)}$ sendo, um momento favorável ao surgimento de problemas, tais como a depressão, a ansiedade e ao cansaço. ${ }^{(8,11,12,14,15)}$

Acresce que, enquanto processo construído em interação, se coloca "como uma problemática feminina, que persiste na contemporaneidade, na medida em que ativa papéis de gênero e contribui para a maior sobrecarga das mulheres". ${ }^{(7)}$
Além disso, o nascimento de um segundo filho também dá origem à fratria e pode desencadear conflitos. ${ }^{(8,11,12,16)}$

Para que a mãe possa oferecer a sua presença e um acolhimento ao segundo filho, precisa de se sentir apoiada, ${ }^{(1,8,15)}$ aspeto que é preponderante neste trajeto adaptativo e de procura de equilíbrio. ${ }^{(1)} \mathrm{O}$ marido exerce aqui uma função de apoio fundamental..$^{(1,7,11,17,18)}$

Embora, ser mãe, de um primeiro ou de um segundo filho, sejam experiências qualitativamente diferenciadas, ${ }^{(17)}$ existem poucos estudos que descrevam a experiência desta transição pela segunda vez, a partir do ponto de vista da mãe, de forma profunda, não se focando apenas na gestação, no pós-parto ou nas semanas imediatamente após o nascimento. ${ }^{(1,11,19-21)}$

$\mathrm{Na}$ revisão "scoping" realizada por Rodrigues e Velez, ${ }^{(21)}$ com os objetivos de identificar e mapear a evidência científica existente sobre a transição da mulher ao tornar-se mãe de um segundo filho, foram identificados 9 estudos publicados entre 1997 e 2013. Nesta revisão conclui-se que mais estudos neste âmbito devem ser efetuados.

É na convergência das dimensóes expostas que foi definida como questáo de pesquisa: qual o sentido a experiência vivida da mulher ao tornar-se mãe de um segundo filho? E como objetivo do estudo compreender, a partir do ponto de vista da mulher, a experiência vivida de se tornar mãe de um segundo filho. Importa aceder à singularidade do(s) mundo(s) vivido(s), atendendo à centralidade da pessoa, que conduza à exploração da essência fenômeno, de modo a que possam ser encontradas formas de cuidar centradas na pessoa e que atendam à sua complexidade, bem como à sua singularidade.

\section{Métodos}

O presente estudo adota uma metodologia qualitativa com abordagem fenomenológica hermenêutica, 
em que as atividades desenvolvidas no processo de análise de dados tiveram em consideração as orientaçôes de Van Manen. ${ }^{(22,23)}$

Foram obtidos os pareceres favoráveis da Comissão deÉtica da EscolaSuperior deEnfermagem de Lisboa (n.o 817/2016) e da Comissão Nacional de Proteção de Dados (n.o 4156/2016). Foram também solicitados os consentimentos das direçóes das creches e das participantes do estudo.

A colheita de dados foi realizada em duas creches privadas de Leiria, Portugal. O material experiencial foi recolhido a partir de entrevistas fenomenológicas, com a duração aproximada de 60 minutos, a 11 mulheres, com um segundo filho, de idade compreendida entre os 18 e os 24 meses. As participantes que preenchiam os referidos critérios de elegibilidade, e com interesse em participar no estudo, foram identificadas conjuntamente pela direção das creches e pelas educadoras.

Foi efetuado um convite por escrito e combinado o momento e local da entrevista de acordo com a preferência das participantes. $\mathrm{O}$ investigador teve treino prévio à realização das entrevistas que decorreram entre março de 2016 e março de 2017, numa sala de reuniôes da creche ou nas casas das participantes.

Estas tinham entre os 26 anos e os 43 anos de idade, coabitavam com os seus companheiros, que eram os pais dos seus filhos. Trabalhavam a tempo inteiro, com exceção de uma das mulheres que estudava. O intervalo de tempo entre o nascimento dos filhos variou entre os 21 meses e os 5 anos.

Seguindo as orientaçôes propostas por Van Manen ${ }^{(22,23)}$ as participantes foram convidadas a identificar uma situação significativa e concreta relativamente à experiência de se tornarem mães de um segundo filho, descrevendo o que aconteceu, o que faziam, disseram e sentiram naquela situação, nomeadamente em relação ao corpo, ao espaço, ao tempo, às coisas e aos outros.

As entrevistas foram gravadas em suporte áudio e transcritas. Seguiu-se um momento de familiarização, com imersão no fenômeno em investigação, através da leitura e re-leitura dos relatos. ${ }^{(22,23)}$

Mobilizando a abordagem descrita por Van Manen ${ }^{(22)}$ foram isolados os temas, ou estruturas experienciais, relativas ao fenômeno. Para essa construção recorreu-se também à análise colaborativa, onde participaram orientadores, docentes e investigadores especialistas em enfermagem pertencentes à área de investigação "Lived experience and epistemology of practice".

\section{Resultados}

Após a análise das narrativas, emergiram quatro temas essenciais: a motivação, o(s) medo(s), a experiência do encontro e do (re)encontro e a experiência do muito e do limite de si: "preciso de mais...".

A experiência do muito e do limite de si: "preciso de mais..." foi um dos temas essenciais identificados. Esta experiência relaciona-se com as inúmeras atividades que as mulheres participantes têm para dar resposta, que as conduzem à experiência do ir além de si, na procura de um novo eu, que quer encontrar o essencial, mas que precisa de ajuda.

Neste artigo é apresentado o tema, a experiência do muito e do limite de si: "preciso de mais..." e os seus quatro subtemas essenciais - "É dar tudo de nós...", "Quero estar aqui, mas também quero estar ali...", A experiência do essencial, $\mathrm{O}$ muito mas com apoio de um outro ...do marido ...da família ...do enfermeiro.

Os extratos das narrativas de seguida apresentadas serão identificadas pela letra $\mathrm{E}$ seguida de número arábico, como forma de manter o anonimato das mulheres participantes no estudo.

\section{"É dar tudo de nós...."}

O muito está de forma continua presente nos relatos das participantes do estudo, como algo que é extremo, em que as participantes revelam dar tudo de si, como que transcendendo o seu eu. Experiência que promove uma dualidade no seu sentir face ao tempo presente vivido, um tempo do quotidiano da mulher, em que atendendo a um tempo passado, se sente sem tempo para si.

Vejamos, as seguintes narrativas:

"É tudo muito, é tudo muito ter dois filhos pequenos. Do bom, e quer dizer, não é mau... Mau de 
cansativo, do que é exigido de nós, de... nos levar à exaustão. Sim, é! É tudo muito" (E1).

"E quando a menina nasceu (...) havia um periodo do dia em que eu tinha de sozinha gerir as tarefas ou as coisas que se têm de fazer: dar comer, preparar o comer, fazer todas as tarefas de casa, no fundo são as coisas que nós temos que fazer" (EO).

"Era o começar de novo. Porque ia... regressar a uma etapa (...) que já estava ultrapassada. O que eu mais sinto, é falta de tempo para mim. (...) é dar tudo de nós." (E3).

O muito, o tudo, quase que um extremo, percorre o tempo destas narrativas, que na sua essência e limite, se assumem, como positivas, como boas, embora para um eu que se sente cansado, no limite de si.

\section{"Quero estar aqui, mas também quero estar ali...} não estava a ser mãe direitinha..."

Procurando compreender a experiência vivida do fenômeno, tornar-se mãe de um segundo filho, identificou-se, como sendo enfatizado pelas participantes, um sentimento de dualidade, de ambivalência, de sofrimento.

As mulheres participantes no estudo relatam que, num mesmo momento, querem estar aqui, querem estar a cuidar de um filho, "mas também quer[em] estar ali”, a cuidar do outro filho. É tal a exigência, que sentem que, naquele tempo, não estão a ser boas mães, ou melhor, não estão a ser mães direitinhas. Sentem que não estão a desempenhar bem o seu papel, não atendendo à individualidade de cada filho. Este sentir é visível nas narrativas que se seguem:

"Então estava a dar banho à mais velha e a mais pequena, no berço, começa a choramingar. À mais velha disse, "olha, espera só um bocadinho, que eu vou ali ver a mana, está bem?" (...) Fui lá num instantinho. Vejo "ok, ok, está tudo bem contigo, tu queres é (...) colo". (..) É complicado (...). Ai, senti-me impotente, (...) eu quero estar aqui, mas também quero estar ali (...)” (E1).
"Dei por mim, às dez da noite, no quarto da garota, sentada numa cadeira, daquelas de criança (...) com ela deitada na cama, a contar-lhe a história, ao mesmo tempo que, estava a dar mama ao garoto. (...) Senti que (...) não estava a ser mãe dos dois e não estava a ser mãe direitinha (...)" (E5).

A tomada de decisão, a escolha, a definição de prioridades, que podem conduzir ao limite, à doença, são vividos pelas participantes neste tempo, como um desafio diário, intenso e constante.

\section{A experiência do essencial}

Neste processo desafiante de tomada de decisão, e de um tempo em que não há tempo, as mulheres participantes aludem à sua experiência vivida, também, como a experiência de encontro com o essencial. No meio do muito e do limite em que vivem, é nos filhos que encontram e (re)encontram o que é essencial às suas vidas, vejamos:

"Uma pessoa não tem tempo, é tudo a correr (...) - De manhá é acordar, é tomar o pequeno almoço [café da manhã], é levá-los à escola, é trabalhar (...). É eles chegarem, é dar banho, é o mais velho estudar, é ter que dar o jantar, (...) ter que orientar as coisas todas em casa. (...) Mas depois quando há aqueles momentos, em que estou mais fragilizada (...). Já me aconteceu com o meu D. dizer-me "oh mäe, eu estou aqui, eu estou aqui, gosto muito de ti (...)" (...) e só aí é que eu caio em mim (...). A coisa mais importante está aqui (...). É fantástico!” (E8).

A valorização do outro, que é filho, de estar com ele, do afeto existente, transforma e dá sentido à vivência desta mulher, permitindo-lhe viver positivamente esta experiência.

\section{0 muito mas o com apoio de um outro... do} marido ...da família ...do enfermeiro A procura de ajuda é o caminho percorrido pelas mulheres participantes, num tempo em que precisam de mais apoio para dar resposta ao momento vivido. Embora com o conhecimento da 
experiência da transição para a parentalidade vivenciada, aquando da presença do primeiro filho, este é um momento que traz novos desafios e responsabilidades, associado a um maior peso sentido e vivido.

O marido assume uma função de apoio fundamental. Na narrativa abaixo apresentada é retratada pela mulher o seu sentir face à sua transição na parentalidade e à dificuldade em dar resposta a tudo, como no tempo passado, situação que, inclusive, despoletou a organização e (re)construção de toda a família num mesmo espaço.

"No inicio se calhar ainda pensamos que as coisas ainda podem continuar como eram antes (...). Mas depois com o segundo começamos a perceber que é difícil conseguir dar resposta a tudo (...) começámos a pensar eu ir viver com ele [na mesma casa]. Náo sei, se por causa da carga, se por causa dele náo participar no quotidiano (...) tanto quanto eu preciso (...) mas a verdade é que eu preciso de mais..." (EO).

Para além do apoio primordial do marido as mulheres participantes referem o apoio de outros elementos da família e dos enfermeiros.

“Tenho um marido que é super! (...) Eles tomam banho juntos, mas eu dou banho a um, ele dá banho ao outro. (...) A minha filha vai agora uma semana para a minha sogra (...). Vai-me custar bastante, mas ainda bem porque ela gosta. Fogo, também preciso de um bocadinho de espaço, eu e o pai." (E6).

"E de repente a enfermeira tem tudo preparado [para vacinar a M.] e diz-me assim "veio sozinha?" (...) e eu (...) "vim, precisamos de mais alguém aqui? Não tinha percebido que precisávamos". E de repente... ela (...) pegou no $H$. ao colo [e] levou-o" (E5).

Este é um período do ciclo vital em que o modo de ser-no-mundo e com-os-outros torna pertinente e necessário o suporte de outros, nomeadamente de uma intervenção profissional.

\section{Discussão}

Tal como desvelado "ser mãe de dois é uma experiência completamente diferente" (E10). Dois filhos, dois seres, uma família, exigem a realização de inúmeras atividades pela mulher, que conduzem à experiência do muito e do limite, do ir além de si, descrito como "o dar tudo de nós".

Neste caminho de procura de um novo eu, de um novo equilíbrio, o tempo assume um valor preponderante. Importa, assim, interrogarmo-nos sobre qual o significado e o sentido do tempo para estas mulheres? Será o tempo do relógio ou será um tempo vivido?

Já O’Reilly ${ }^{(1)}$ no estudo que desenvolveu - e onde procurou descrever a experiência de transição para a parentalidade, a partir da perspetiva da mulher, que é mãe pela segunda vez - identificou o tema, "fazendo uma pausa”. Este tema emergiu como um elemento comum, na medida em que as participantes referiam sentir necessidade de fazer uma pausa, embora esta vontade assumisse baixa prioridade, atendendo a tantas outras coisas que tinham para fazer.

Heidegger propóe o tempo como horizonte de toda compreensão e interpretação do ser como "função ontológica fundamental". ${ }^{(2,3)}$ Nas suas palavras "se o ser deve ser apreendido a partir do tempo e os diversos modos e derivados do ser só são de fato compreensíveis em suas modificaçôes e derivaçôes na perspetiva do tempo e com referência a ele, o que então se mostra é o próprio ser, e não apenas o ente, enquanto sendo e estando "no tempo", em seu caráter "temporal" ". $(2,3)$

Assim, envolvidas neste tempo presente, que volta ao passado e se projeta no futuro, as participantes vivem também um tempo de dualidade, em que "quererem estar aqui, mas também ali...", em que "sentem que não são mães direitinhas", que não cumprem o seu papel maternal. Este sentir ambivalente provoca-lhes sofrimento, pois têm de decidir, têm de definir prioridades, o que exige autodomínio. Também Santos ${ }^{(24)}$ e Henriques ${ }^{(25)}$ nos estudos que desenvolveram retratam este lado mais obscuro da maternidade. ${ }^{(26)}$

Todavia, para as mulheres participantes, o essencial, está lá. O essencial que é o outro, a presença 
do outro... Mas, para tal, é preciso vê-lo, pois tal como refere Merleau-Ponty ${ }^{(27)}$ "ver, é em princípio, ver mais do que se vê".

O marido, a família, o enfermeiro, orientam o caminho destas mulheres. Em vários estudos, estes intervenientes também são identificados como facilitadores desta transição. ${ }^{(1,24,28)}$ Contudo, uma vez que ser um filho, é diferente de serem dois, a disponibilidade das figuras de apoio pode não ser total, mas contada. Também Santos, ${ }^{(24)}$ no estudo que desenvolveu, destaca que a preparação insuficiente para o desempenho do papel materno, por parte dos profissionais de saúde, é identificada, pelas participantes, como elemento dificultador desta transição.

Importa questionar sobre qual o lugar do homem, do companheiro, do pai, nesta transiçáo? Traduz-se no suporte à mulher e/ou nos cuidados aos filhos? Vários estudos, com enfoque nesta transição, apontam para as questôes de género, de relacionamento e de satisfação conjugal, ${ }^{(11,12,29-33)}$ nomeadamente para o maior conflito de papéis e isolamento relatados pelas mulheres na vivência desta transição na parentalidade. A comunicação conjugal, a depressão e o apoio social são apontado como alvos importantes de intervenção. ${ }^{(12)}$

Náo obstante, para as mulheres participantes esta é uma experiência de pequenas grandes coisas. É acima de tudo uma "experiência positiva".

Embora se constitua como limitação o facto dos achados aqui apresentados, apenas retratarem um dos temas essenciais identificados, os mesmos possibilitam uma abertura à compreensão do fenómeno, não sendo possível, nem pretendido, a sua representatividade ou extrapolação. ${ }^{(23)}$

A facilitação dos processos de transição constitui-se como um foco de atenção da disciplina de enfermagem, ${ }^{(34,35)}$ sendo que a vivência deste fenómeno exige a operacionalização de um cuidado humano profissional dirigido ao reforço de competências, à identificação de recursos e à minimização de vulnerabilidades. ${ }^{(7)} \mathrm{O}$ encontro com os achados apresentados e o seu sentido para os enfermeiros permitirá abrir o horizonte da sua compreensão da experiência vivida destas mulheres e seguramente terá impacto no seu modo de ser-presente no quotidiano de cuidados.

\section{Conclusão}

Ser mãe de dois é uma experiência completamente diferente, na medida em que dois filhos, dois seres, uma família, exige a realização de inúmeras atividades pela mulher, que conduzem à experiência do muito e do limite, do ir além de si, na procura de mais e de um novo eu que quer encontrar o essencial. Aceder à experiência humana da mulher ao tornar-se mãe de um segundo filho, de forma singular e conforme é vivida, promove a desocultação e a compreensão da essência deste fenômeno, produzindo-se conhecimento que sustenta formas de cuidar centradas na pessoa e que atende à sua complexidade, bem como à sua singularidade, sustentando o processo de tomada de decisão inerente a uma prática de cuidados de enfermagem baseada na evidência.

\section{Agradecimentos}

À UI\&DE pelo apoio financeiro para a publicação deste artigo.

\section{Colaborações}

Rodrigues J e Rebelo-Botelho MA contribuíram com a concepção do projeto, análise e interepretação dos dados, redação do artigo, revisão crítica revelante do conteúdo intelectual e aprovação da versão final a ser publicada.

\section{Referências}

1. O'Reilly MM. Achieving a new balance: women's transition to secondtime parenthood. J Obstet Gynecol Neonatal Nurs. 2004;33(4):45562.

2. Heidegger M. Ser e tempo. Petrópolis: Editora Vozes; 2006. [Tradução do original publicado em 1927].

3. Heidegger M. Being and time. Oxford: Blackwell; 2001.

4. Watson J. Enfermagem: ciência humana e cuidar uma teoria de enfermagem. Loures: Lusociência; 2002.

5. Watson J. A Theory of nursing. 2nd ed. London: Jones and Bartlett Learning; 2012. 
6. Mercer RT. Nursing support of the process of becoming a mother. $J$ Obstet Gynecol Neonatal Nurs. 2006 Sep;35(5):649-51.

7. Martins C. A transição no exercício da parentalidade durante o primeiro ano de vida da criança: uma teoria explicativa de enfermagem [tese]. Lisboa: Universidade de Lisboa; 2013.

8. Vivian A. Tornar-se mãe de um segundo filho: da gestação ao segundo ano de vida [tese]. Porto Alegre: Universidade Federal do Rio Grande do Sul; 2010.

9. Mercer RT. Becoming a mother versus maternal role attainment. J Nurs Scholarsh. 2004;36(3):226-32.

10. Moura-Ramos M, Canavarro M. Adaptação parental ao nascimento de um filho: comparação da reactividade emocional e psicossintomatologia entre pais e mães nos primeiros dias após o parto e oito meses após 0 parto. Aná Psicol. 2007;3(25):399-413.

11. Kuo PX, Volling BL, Gonzalez R. His, hers, or theirs? Coparenting after the birth of a second child. J Fam Psychol. 2017;31(6):710-20.

12. Volling BL, Oh W, Gonzalez R, Kuo PX, Yu T. Patterns of marital relationship change across the transition from one child to two. Couple Family Psychol. 2015;4(3):177-97.

13. Nichols MR, Roux GM, Harris NR. Primigravid and multigravid women: prenatal perspectives. J Perinat Educ. 2007;16(2):21-32.

14. Tavares M. Transição para a parentalidade e a saúde mental no puerpério: significados para a mulher em risco de depressão pós-parto [tese]. Lisboa: Universidade do Porto; 2014.

15. Gottlieb LN, Mendelson MJ. Mothers' moods and social support when a second child is born. Matern Child Nurs J. 1995;23(1):3-14.

16. Goldsmid R, Féres-Carneiro T. Fraternal relationship: subject's constitution and the formation of social ties. Psicol USP. 2011;22(4):771-8.

17. Gottlieb LN, Baillies J. Firstborns' behaviors during a mother's second pregnancy. Nurs Res. 1995;44(6):356-62.

18. Passos M. Nem tudo que muda, muda tudo: um estudo sobre as funções da família. Féres-Carneiro, T. Família e casal: efeitos da contemporaneidade. Rio de Janeiro: PUC RI0; 2009. p. 11-23.

19. Kojima $M$, Wakita $M$, Irisawa $Y$. The impact of a second infant on interactions of mothers and firstborn children. J Reprod Infant Psychol. 2005;23(1):103-14.

20. Holditch-Davis D, Miles M. Parenting research in nursing. In: Fitzpatrick J, Wallace M, editors. Encyclopedia of nursing research. NY: Springer; 2012. p. 374-6.
21. Rodrigues J, Velez M. Tornar-se mãe de um segundo filho: uma revisão scoping. Pensar Enfermagem. 2018;22(1):5-17.

22. Van Manen $M$. Researching lived experience, human science for an action sensitive pedagogy. 2nd ed. Ontario: The Althouse Press; 2003.

23. Van Manen M. Phenomenology of practice: meaning-giving methods in phenomenological research and writing. CA: Left Coast Press; c2014.

24. Santos M. 0 processo de metamorfose da mulher acima dos trinta e cinco anos em mãe - uma teoria específica da situação [tese]. Lisboa: Universidade de Lisboa. 2018.

25. Henriques C. Transição para o papel maternal: a experiência vivida de mulheres com problemas de adição a substâncias psicoativas [tese]. Lisboa: Universidade de Lisboa. 2018.

26. Nunes B. Heidegger \& Ser e Tempo. Rio de Janeiro: Jorge Zahar Editor; 2002

27. Merleau-Ponty M. Signos. Barcelona: Editorial Seix Barral; 1964.

28. Piccinini C, Pereira C, Marin A, Lopes RC, Tudge J. 0 Nascimento do Segundo Filho e as Relações Familiares. Psicol, Teor Pesqui. 2007;23(3):253-61.

29. Krieg D. Does motherhood get easier the second-time around? Examining parenting stress and marital quality among mothers having their first or second child. Parent Sci Pract. 2007;7(2):149-75.

30. Möller K, Hwang C, Wickberg B. Couple relationship and transition to parenthood: does workload at home matter? J Reprod Infant Psychol. 2008;26(1):57-68.

31. Hakulinen T, Paunonen M, White MA, Wilson ME. Dynamics of families during the third trimester of pregnancy in southwest Finland. Int J Nurs Stud. 1997;34(4):270-7.

32. Katz-Wise SL, Priess HA, Hyde JS. Gender-role attitudes and behavior across the transition to parenthood. Dev Psychol. 2010;46(1):18-28.

33. Szabó N, Dubas JS, van Aken MA. And baby makes four: the stability of coparenting and the effects of child temperament after the arrival of a second child. J Fam Psychol. 2012;26(4):554-64.

34. Meleis Al, Sawyer LM, Im EO, Hilfinger Messias DK, Schumacher K. Experiencing transitions: an emerging middle-range theory. ANS Adv Nurs Sci. 2000;23(1):12-28.

35. Meleis A. Transitions theory: middle range and situation specific theories in nursing research and practice. New York: Springer; 2010. 